Bangladesh J. Bot. 47(4): 815-821, 2018 (December)

\title{
ORGANO - MINERAL FERTILIZATION OF WHEAT: IMPACT ON GROWTH AND N - RECOVERY USING ${ }^{15} \mathbf{N}$ - STABLE ISOTOPE
}

\author{
MM Ismail ANd Ahmed A Moursy* \\ Atomic Energy Authority, Nuclear Research Center, \\ Soil and Water Research Department, Abou-Zaabl, 13759, Egypt \\ Keywords: Sand soil, Wheat plants, Organic materials, Ammonium sulphate fertilizer, \\ Bio-fertilizer and ${ }^{15} \mathrm{~N}$
}

\begin{abstract}
Investigation was carried out to follow up the effect of organo-mineral fertilizers on yield of wheat plants grown on sand soil using ${ }^{15} \mathrm{~N}$ stable isotope. Dry matter accumulation of wheat straw yielded 14.70 g/pot and grains yielded $12.72 \mathrm{~g} /$ pot with application of $50 \%$ As + BF. The highest values of N-uptake by straw and grains were $144.08 \mathrm{mg} \mathrm{N} /$ pot and $320.54 \mathrm{mg}$ N/pot, respectively when treated with 50\% As + BF. Portions of different $\mathrm{N}$ sources i.e. Nitrogen derived from fertilizer (\% Ndff), nitrogen derived from air (\% Ndfa) and fertilizer use efficiency (\% FUE), gained by grains were (\% 28.20), (\% 19.70) and (\% 34.31) as affected by addition of (50\% ammonium sulphate (As) + Bio fertilizer, (25\% rice straw (Rs) $+25 \%$ As + BF) and ( $25 \%$ chicken manure $(\mathrm{CM})+25 \%$ As $+B F)$, respectively.
\end{abstract}

\section{Introduction}

Application of mineral fertilizers, especially $\mathrm{N}$ fertilizer, compensated the increase in grain demand of the growing population. Nevertheless, numerous issues have emerged with increasing application rate of $\mathrm{N}$ fertilizers; such issues include reduced $\mathrm{N}$ use efficiency and aggravated fertilizer losses through ammonium volatilization, denitrification, leaching, and runoff, which may generate environmental risks (Zhu and Chen 2002). Therefore, mineral fertilizer N supply must be synchronized with crop demand (Bindraban et al. 2015).

Wheat (Triticum aestivum L.) is one of the major cereal crops with a unique protein, which is consumed by humans and is grown around the world in diverse environments (Abedi et al. 2010). In Egypt, its production does not meet the current demand. The Egyptian government is giving many efforts to reduce the imported percentage to be less than $50 \%$ from the total consumption (Shaaban 2006). Nitrogen $(\mathrm{N})$ is the most important nutrient supplied to most non-legume crops, including wheat. Thus, $\mathrm{N}$ supply to the plant will influence the amount of protein, amino acids, protoplasm and chlorophyll. Moreover, it influences the cell size, leaf area and photosynthetic activity (Diacono et al. 2013). Agricultural organic wastes, especially straw, are considered as important $\mathrm{N}$ source in agricultural production. Burning straw for managing excessive crop residues is a common practice that has resulted in greenhouse gas emissions and organic N losses (Singh et al. 2005), which can be addressed by returning straw to farmland (Dominguez- Escriba and Porcar 2010). The combined application of straw with mineral fertilizer $\mathrm{N}$ reduces the superfluous accumulation of mineral $\mathrm{N}$ in soil and its losses (Wang et al. 2015). Microbial immobilization of applied $\mathrm{N}$ can effectively prevent $\mathrm{N}$ losses during the early growth stages when the demand for $\mathrm{N}$ remains low, whereas demineralization may enhance soil $\mathrm{N}$ supply when plant $\mathrm{N}$ demand increases (Sugihara et al. 2010). Many attempts have been taken to replace a part of those harmful fertilizers by bio-fertilizers in crop plants to get as yield of good quality without loss in its quantity (El-Kholy et al. 2011). Inoculation of maize and wheat

*Author for correspondence: <ahmad1a2m3@yahoo.com>. 
seeds with Azotobacter and Azospirillum increased plant growth, nutrients uptake and yield (Dobbelaere et al. 2011). Aim of the present study was to investigate the effect of bio-organic and inorganic $\mathrm{N}$ fertilizers individually or in combination on growth and yield of wheat plants grown on sand soil with application of ${ }^{15} \mathrm{~N}$ tracer technique.

\section{Materials and Methods}

A pot experiment was carried out at the Plant Nutrition and Fertilization Unit, Soils and Water Research Department, Nuclear Research Center, Atomic Energy Authority, Inshas, Egypt.

Sand soil used as growth medium was collected from the surface layer $(0-15 \mathrm{~cm})$ of Inshas area, Sharkia Governorate and air dried, ground and sieved to pass through a $2 \mathrm{~mm}$ sieve. Next the samples were subjected to physical and chemical analysis. The physical and chemical properties of the sandy soil were $88.5 \%$ sand, $2.7 \%$ silt, $8.8 \%$ clay, $\mathrm{pH} 1: 2.5$ suspension 7.97 , EC 0.27 $\mathrm{dS} / \mathrm{m}^{-1}$, OC $0.017 \%$, organic matter $0.03 \%$, total $\mathrm{N} 0.007 \%$, C/ $\mathrm{N}$ ratio 2.43 and $\mathrm{CaCO}_{3} 1.0 \%$.

Seeds of wheat cultivar (Triticum aestivum C.V. Sakha 6), were collected from the Agriculture Research Centre (ARC), Giza, Egypt. Rice straw (RS) as plant residues and chicken manure (CM) as organic manure were used in this study. RS and CM were air-dried, ground, thoroughly mixed and subjected to some chemical analysis. Both of them were incorporated into the soil one month before cultivation. Rice straw have O.C 36.0\%, T.N 0.5\%, C/N ratio 72, pH (1: 5) 7.18, EC (dS/ m) 4.7; and chicken manure have organic carbon (O.C) 52.0\%, total nitrogen (T.N.) 4.0\%, C/N ratio 13, pH (1: 5) 8.12, EC (dS/ m) 8.16.

${ }^{15} \mathrm{~N}$-labeled ammonium sulfate $\left(2 \%{ }^{15} \mathrm{~N}\right.$ atom excess) was applied as a source of mineral nitrogen and applied as solution one time after two weeks from planting. Bio fertilizer (BF): Efficient strains of associative- $\mathrm{N}_{2}$ fixing bacteria (Azotobacter) obtained from Microbiology Department, Soils, Water and Environment Research Institute, ARC, Giza, Egypt was used.

Plastic pots of $20 \mathrm{~cm}$ in diam. and $30 \mathrm{~cm}$ in height were uniformly packed with portions of air-dried and screened soil $(5 \mathrm{~kg} / \mathrm{pot})$. Each pot was sown with 10 wheat grains, which were thinned to 5 plants after 14 days from planting. The pots were arranged into two groups, each of which conducted in a completely randomized block design with three replicates.

Sources of applied organic nitrogen (RS and CM), Azotobacter inoculation, and $\mathrm{N}$ fertilizer applied at the rate of $120 \mathrm{~kg} \mathrm{~N} / \mathrm{fed}$ (equal to $600 \mathrm{mg} \mathrm{N} / \mathrm{pot}$ ), and $60 \mathrm{~kg} \mathrm{~N} / \mathrm{fed}$ (equal to $300 \mathrm{mg}$ $\mathrm{N} /$ pot) as labelled ammonium sulfate with $2 \%{ }^{15} \mathrm{~N}$ a.e., were applied after 14 days from planting.

Inoculated or un-inoculated wheat were seeded in the prepared pots and treated with nitrogen as follows: (1) Control, (2) $100 \%$ RS, (3) $50 \%$ RS + 50\% AS, (4) $100 \%$ CM, (5) $50 \% \mathrm{CM}+50 \%$ AS, (6) $100 \%$ AS, (7) Control + BF, (8) $50 \%$ RS + BF, (9) $25 \%$ RS + 25\% AS +BF; $10-50 \%$ $\mathrm{CM}+\mathrm{BF}$; $11-25 \% \mathrm{CM}+25 \%$ AS +BF; $12-50 \%$ AS + BF. After harvest (143 days from sowing), the dry weight of whole plants and plant parts, total nitrogen, \% Ndff, \% Ndfs, \% Ndfa and FUE were calculated.

Chemical and physical analysis of experimental soil samples were determined according to Page et al. (1982) and Black (1965).

Isotope dilution concept and standard equations were used for quantifying nitrogen derived from fertilizer (Ndff), from soil ( Ndfs), from air (Ndfa) and nitrogen use efficiency (NUE) which recovered by wheat plants according to Training Course series No. 14, IAEA (2001).

Results were subjected to AVOVA analysis followed by DMRT according to SAS software program SAS (1987). 


\section{Results and Discussion}

Data illustrated by Figs 1 and 2 showed that, in general, the dry matter yield of wheat plants was not significantly affected by sole bacterial inoculation. However, combined treatment of BF with both organic and inorganic nitrogen significantly increased the dry matter of wheat plants as compared with the untreated control. Furthermore, the highest values of straw yield (14.70 g/pot) and grain yield (12.72 g/pot) were recorded by application of $50 \%$ AS + BF. In case of uninoculated plants, higher values of straw and grain yields (14.02 g/pot and $11.92 \mathrm{~g} /$ pot $)$ were recorded by application of $100 \%$ AS. According to Namvar and Khandan (2013) moderate N rate (about $150 \mathrm{~kg} \mathrm{~N} / \mathrm{ha}$ ) can be beneficial to improve growth, development and total yield of inoculated wheat. This finding is, to some extent, similar to the present result. Suresh et al. (2017) also reported that all fertilized treatments improved the productivity relative to control (unfertilized). Wheat yield with synthetic fertilizer (NPK) was 42\% more compared with control, and further increased with layering of organic and inorganic fertilizers along with bio-fertilizers. Similarly, Sarma et al. (2007) who observed application of $150 \mathrm{~kg} \mathrm{~N} / \mathrm{ha}+$ farm yard manure $(\mathrm{FYM})(10 \mathrm{t} / \mathrm{ha})+$ Azotobacter, recorded significantly higher grain yield by $10 \%$ compared to 150 $\mathrm{kg} \mathrm{N} /$ ha and FYM $10 \mathrm{t} / \mathrm{ha}$ (4.34 t/ha).

From greenhouse research Alshankiti and Gill (2016) suggested a positive interaction between compost, biochar (BC) and bio-fertilizers on maize crop productivity. The combined effect of the three was a multi-folds increase in biomass of maize. Biochar application affected significantly to soil chemical properties such as organic carbon (OC) and cation exchange capacity (CEC). This approach could be of particular significance for sandy soils that not only lack organic matter but also microbial population and biodiversity. The integrated use of compost, biochar and biofertilzers has proved to be an eco-friendly approach, affordable by farmers and has the potential to play key role in crop productivity improving soil health.

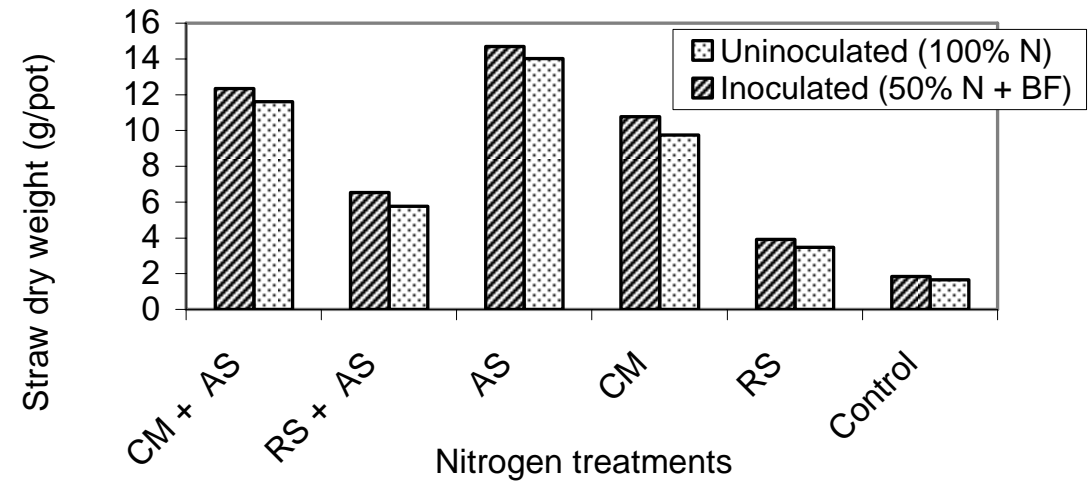

Fig. 1. Dry matter yield of wheat straw (g /pot) as affected by organic materials and/or ${ }^{15} \mathrm{~N}$-labelled ammonium sulfate with or without bio-fertilizer.

The use of Azotobacter inoculation alone or in combination with organic and inorganic Nfertilizer significantly increased $N$ uptake in straw and grain of wheat (Figs 3 and 4). Combined treatment of bio-fertilizer with both organic and inorganic nitrogen fertilizers, revealed that the highest $\mathrm{N}$-content in straw was $144.08 \mathrm{mg} \mathrm{N} /$ pot and in grain yield was $320.54 \mathrm{mg} \mathrm{N} /$ pot as affected by addition of ( $50 \%$ AS* $+\mathrm{BF}$ ). These results are in conformity with the results reported by Shah and Ishaq (2006), who had reported that combination of organic and inorganic $\mathrm{N}$ resulted 
in greater N-uptake from than those obtained when each was applied separately. In other field study application of FYM, vermicomposting and inorganic fertilizers with Azotobacter strain significantly $(\mathrm{p}=0.05)$ increased the NPK uptake by the crop than the application of zero fertilizer as well as chemical fertilizers alone (Suresh et al. 2017). Maximum NPK uptake by the crop was recorded from organic, inorganic and biofertilizer treated plots. On the same line, Devi et al. (2011) had reported that integrated nutrient management (INM) produced higher yield attributes and grain yield than the NPK fertilizers alone, the higher yield led to higher NPK uptake by wheat.

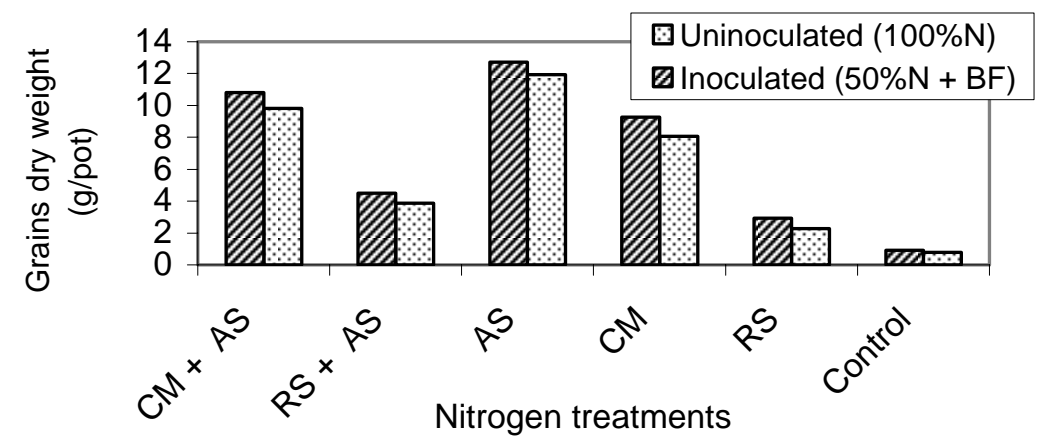

Fig. 2. Dry matter yield of wheat grains (g/pot) as affected by organic materials and/or ${ }^{15} \mathrm{~N}$-labelled ammonium sulfate with or without bio-fertilizer.

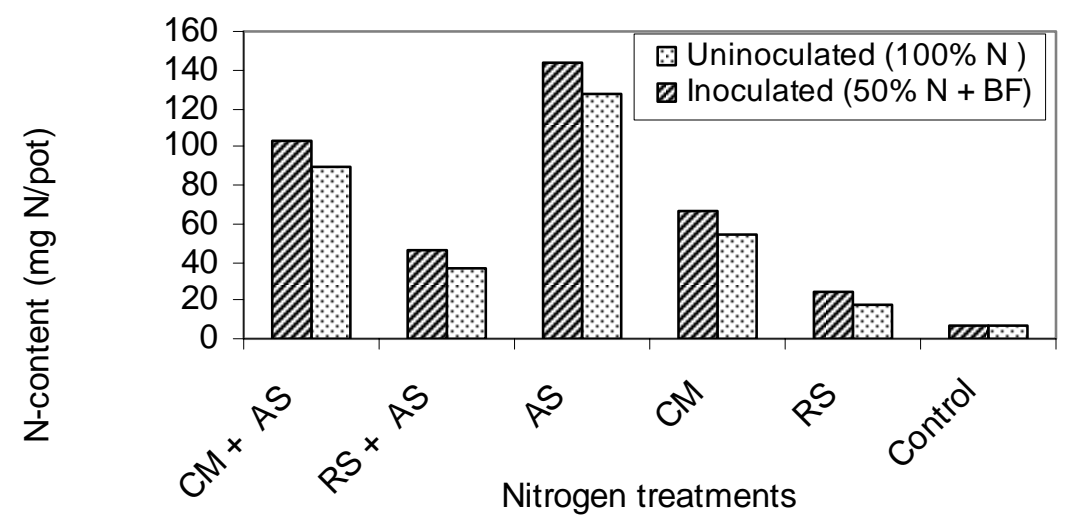

Fig. 3. Nitrogen content of wheat straw (mg N/pot) as affected by organic materials and/or ${ }^{15} \mathrm{~N}$-labelled ammonium sulfate with or without bio-fertilizer.

\footnotetext{
${ }^{15} \mathrm{~N}$-isotope dilution technique: Nitrogen derived from fertilizer (\% Ndff), soil (\% Ndfs), air (\% Ndfa) and fertilizer use efficiency (FUE) by wheat straw and grain: Data illustrated by Fig. 5 showed that, in general, percentage of nitrogen derived from fertilizer (\% Ndff ), nitrogen derived from soil and nitrogen derived from (\% Ndfa) markedly fluctuated between the increase and decrease due to addition of bio-organic and inorganic nitrogen fertilizers either applied alone or in combinations on the basis of their $\mathrm{N}$ content. Moreover, for nitrogen derived from fertilizer (\% Ndff), the highest percentage of nitrogen utilized by straw and grain of non and inoculated wheat plants were 45.41 and $25.50 \%$ and 48.90 and $28.20 \%$ achieved by addition of (100\% AS) and (100\% AS + BF), respectively.
} 
Concerning N-derived from soil (\% Ndfs), the highest percentages were 68.17, and 64.29\% and 64.90 and $64.68 \%$ recorded with the rates of (50\% RS + 50\% AS) and (25\% CM + 25\% AS + $\mathrm{BF}$ ) for the same sequence. Nitrogen derived from air (\% Ndfa), utilized by straw and grain were 20.70 and $19.70 \%$ achieved by the rate of ( $25 \%$ RS $+25 \%$ AS + BF). Accordingly, the percentage of Ndfs was found to be higher than those of Ndff and \% Ndfa. Similar results were reported by Azam et al. (2009) who had stated that the percentage of Ndfs was found to be higher compared to Ndff.

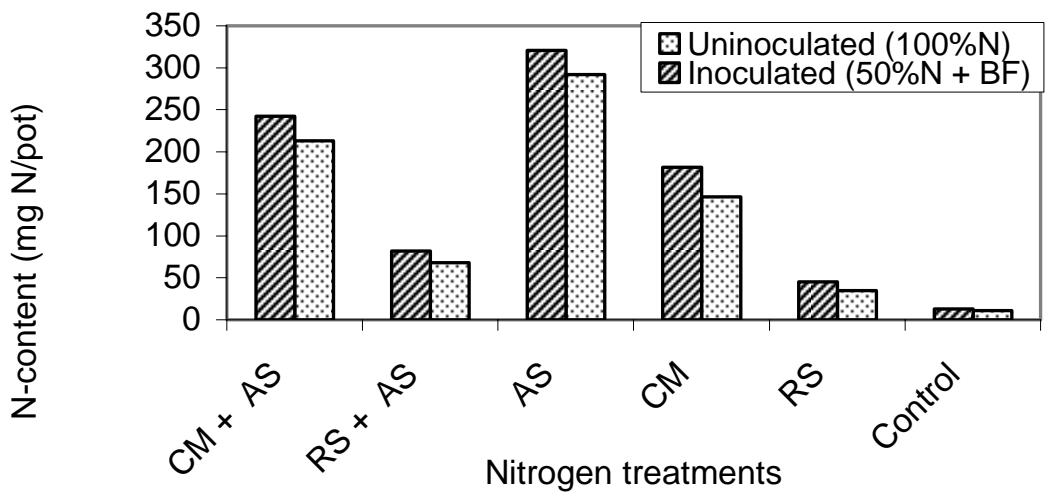

Fig. 4. Nitrogen content of wheat grains (mg N/pot) as affected by organic materials and/or ${ }^{15} \mathrm{~N}$-labelled ammonium sulfate with or without bio-fertilizer.

Concerning fertilizer use efficiency (\% FUE) of wheat straw and grains, the highest percentages were $(10.40,28.10),(12,25,26.14)$ and $(11.90,34.31)$ achieved by the utilized rates of $(50 \% \mathrm{CM}+50 \% \mathrm{AS}),(50 \% \mathrm{AS}+\mathrm{BF})$ and $(25 \% \mathrm{CM}+25 \% \mathrm{AS}+\mathrm{BF})$ ratios, respectively. Previously, Safwat et al. (2001) had stated that agronomic efficiency and nitrogen use efficiency were also found to be higher in the treatment of $25 \% \mathrm{~N}$ applied as poultry manure and $75 \%$ from mineral fertilizer. They concluded that combination of $25: 75$ organic to mineral $\mathrm{N}$ sources were the best combination that achieved sustainable yield.

In the same way, Yaduvanshi (2003) had reported that conjunctive application of urea and FYM resulted in the increased fertilizer nitrogen recovery relative to other treatment both by rice (30.6\%) and wheat (2.2\%). Suresh et al. (2017) also found that FYM, vermicompost (VC) and NPK fertilizers with Azotobacter strain resulted in an increase of the nitrogen, phosphorus and potassium use efficiency by the crop than the application of zero fertilizer as well as chemical fertilizers alone. Fertilizer-use efficiency, i.e. partial factor productivity (PFP) agronomic efficiency (AE), apparent recovery efficiency (RE), and physiological efficiency were significantly improved with the application of manures, chemical fertilizers and bio-fertilizer over control as well as chemical fertilizer alone.

Previous work carried out by Malika et al. (2015) had revealed that inorganic, organic and biofertilizer combinations significantly increased the agronomic efficiency and apparent $\mathrm{N}$ recovery. Similarly results recorded by Jat et al. (2015) indicated that nutrient use efficiency was greatly increased by balanced use of $\mathrm{N}, \mathrm{P}$ and $\mathrm{K}$ fertilizers and by rational use of organic manures in wheat systems. It might be due to beneficial effect of combined application of organic manures and inorganic fertilizers on crop growth, which influenced the growth and yield-attributing characters positively. Moreover, proper decomposition of FYM, VC which supplied available plant nutrients directly to plants and created favourable soil environment and ultimately increased 
the nutrients and water-holding capacity of soil for longer time. This resulted in better growth, yield attributes and ultimately grain and straw yields of wheat.

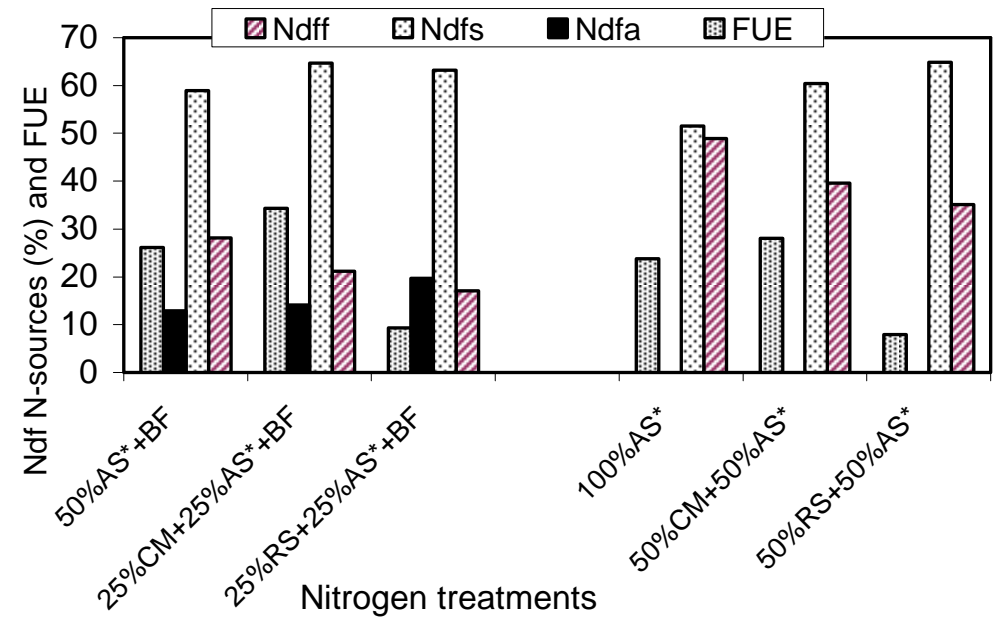

Fig. 5. Percentage of Ndff, Ndfs, air and FUE of wheat straw as affected by organic materials and/or ${ }^{15} \mathrm{~N}$-labelled ammonium sulfate with or without bio-fertilizer.

Recently, the use of bio-organic fertilizers in agriculture has received a considerable attention because of the environmental problems. The combined effect of $50 \%$ recommended chemical fertilizer $\mathrm{N}+$ organic fertilizer + bio-fertilizer gave the best results. Therefore, the combination of $\mathrm{N}$-fertilizer at $50 \%$ of the recommended dose with bio-organic fertilizers could be positively effective in wheat production under such poor nutrients sand soil.

\section{References}

Abedi T, Alemzadeh A, Kazemeini SA 2010. Effect of organic and inorganic fertilizers on grain yield and protein banding pattern of wheat. Australian J Crop Sci. 6(4): 384-389.

Alshankiti A and Gill S 2016. Integrated Plant Nutrient Management for sandy soil using chemical fertilizers, compost, biochar and biofertilizers - Case study in UAE. J. Arid Land Studies 26(3): 101-106.

Azam Shah S, Mahmood Shah S, Mohammad W, Shafi M and Nawaz H 2009. N uptake and yield of wheat as influenced by integrated use of organic and mineral nitrogen. International Journal of Plant Production 3(3): 1735-6814 .

Bindraban PS, Dimkpa C, Nagarajan L, Roy A, Rabbinge R 2015. Revisiting fertilisers and fertilisation strategies for improved nutrient uptake by plants. Biol. Fert. Soils 51: 897-911.

Black CA 1965. Methods of Soil Analysis, ASA, SSSA, Madison, Wisconsin, USA.

Devi KN, Singh MS, Singh NG and Athokpam HS 2011. Effect of integrated nutrient management on growth and yield of wheat (Triticum aestivum L. J. Crop and Weed 7(2): 23-27.

Diacono M, Rubino P and Montemurro F 2013. Precision nitrogen management of wheat: A review. Agronomy for Sustainable Development 33(1): 219-241.

Dobbelaere S, Croonenborghs A, Thys A, Ptacek D, Vanderleyden J, Dutto P, Labandera-Gonzalez C, Caballero-Mellado J, Aguirre F, Kapulnik Y, Brener S, Burdman S, Kadouri D, Sarig S, Okon Y 2011. Response of agronomically important crops to inoculation with Azospirillum. Australian J. Plant Physiology 28: 871-879.

Dominguez-Escriba L and Porcar M 2010. Rice straw management: The big waste. Biofuel Bioprod Bior 4: 154-159. 
El-Kholy M A, El-Ashry S and Gomaa AM 2011. Biofertilization of maize crop and its impact on yield and grains nutrient content under low rates of mineral fertilizers. J. Applied Sciences Research 2: 117-121.

IAEA, Vienna 2001. Use of isotope and radiation methods in soil and water management and crop nutrition. Manual. Training Course Series No. 14. IAEA, Vienna.

Jat LK, Singh YV, Meena SK, Meena SK, Parihar M, Jatav HS, Meena RK and Meena VS 2015. Does Integrated Nutrient Management, Enhance Agricultural Productivity. Journal of Pure and Applied Microbiology 9(2): 1211-1221.

Malika M, Islam MR, Karim R, Huda A and Jahiruddin M 2015. Organic and inorganic fertilizers influence the nutrient use efficiency and yield of a rice variety BINA dhan7. Academic Res. J. Agri. Sci. Res. 3(7): 192-200.

Namvar A and Khandan $\mathrm{T}$ 2013. Response of wheat to mineral nitrogen fertilizer and biofertilizer (Azotobacter sp. and Azospirillum sp.) inoculation under different levels of weed interference. EKOLOGIJA 59(2): 85-94.

Page AL, Miller RH and Kenney DR 1982. Methods of Soil Analysis, Part 1, ASA, SSSA, Madison, Wisconsin, USA.

Sarma A, Singh H and Nanwal RK 2007. Effect of integrated nutrient management on productivity of wheat (Triticum aestivum) under limited and adequate irrigation supplies. Indian J. Agronomy 52(2): 120-123.

SAS Institute 1987 AS/STATTM Guide for personal computers. Version 6 edition, SAS Institute Inc, Cary, NY.

Shaaban SM 2006. Effect of organic and inorganic nitrogen fertilizer on wheat plant under water regime. J. Applied Sci. Res. 2(10): 650-656.

Shah Z and Ishaq M 2006. Effect of integrated use of farm yard manure and urea on yield and nitrogen uptake of wheat. J. Agri. Bio. Sci. 1(1): 60-64.

Singh G, Jalota SK and Sidhu BS 2005. Soil physical and hydraulic properties in a rice-wheat cropping system in India: Effects of rice-straw management. Soil Use Manage 21: 17-21.

Sugihara S, Funakawa S, Kilasara M and Kosaki T 2010. Dynamics of microbial biomass nitrogen in relation to plant nitrogen uptake during the crop growth period in a dry tropical cropland in Tanzania. Soil Sci.i Plant Nutr. 56: 105-114.

Suresh Kumar Kakraliya, RD Jat, Sandeep Kumar, KK Choudhary, Jai Prakash and Singh LK 2017. Integrated nutrient management for improving, fertilizer use efficiency, soil biodiversity and productivity of wheat in irrigated rice wheat cropping system in Indo Gangatic plains of India. Int. J. Curr. Microbiol. App. Sci. 6(3): 152-163.

Wang J, Zhu B, Zhang JB, Muller C, Cai ZC 2015. Mechanisms of soil N dynamics following long-term application of organic fertilizers to subtropical rain-fed purple soil in China. Soil Biol. Biochem. 91: 222-231.

Yaduvanshi NPS 2003. Substitution of inorganic fertilizers by organic manures and the effect in soil fertility in a rice-wheat. Rotation on reclaimed sodic soil in India. Indian J. Agri. Sci. 140: 161-169

Zhu ZL and Chen DL 2002. Nitrogen fertilizer use in China-contributions to food production, impacts on the environment and best management startegies. Nutr. Cycl. Agroecosys 63:117-127. 